\title{
Individual education, area income, and mortality and recurrence of myocardial infarction in a Medicare cohort: the National Longitudinal Mortality Study
}

Sean A Coady ${ }^{1 *}$, Norman J Johnson ${ }^{2+}$, Jahn K Hakes ${ }^{2+}$ and Paul D Sorlie ${ }^{1+}$

\begin{abstract}
Background: The Medicare program provides universal access to hospital care for the elderly; however, mortality disparities may still persist in this population. The association of individual education and area income with survival and recurrence post Myocardial Infarction (MI) was assessed in a national sample.

Methods: Individual level education from the National Longitudinal Mortality Study was linked to Medicare and National Death Index records over the period of 1991-2001 to test the association of individual education and zip code tabulation area median income with survival and recurrence post-MI. Survival was partitioned into 3 periods: in-hospital, discharge to 1 year, and 1 year to 5 years and recurrence was partitioned into two periods: 28 day to 1 year, and 1 year to 5 years.

Results: First Mls were found in 8,043 women and 7,929 men. In women and men 66-79 years of age, less than a high school education compared with a college degree or more was associated with 1-5 year mortality in both women (HRR 1.61, 95\% confidence interval 1.03-2.50) and men (HRR 1.37, 1.06-1.76). Education was also associated with 1-5 year recurrence in men (HRR 1.68, 1.18-2.41, < High School compared with college degree or more), but not women. Across the spectrum of survival and recurrence periods median zip code level income was inconsistently associated with outcomes. Associations were limited to discharge-1 year survival (RR lowest versus highest quintile 1.31, 95\% confidence interval 1.03-1.67) and 28 day-1 year recurrence (RR lowest versus highest quintile 1.72, 95\% confidence interval 1.14-2.57) in older men.
\end{abstract}

Conclusions: Despite the Medicare entitlement program, disparities related to individual socioeconomic status remain. Additional research is needed to elucidate the barriers and mechanisms to eliminating health disparities among the elderly.

Keywords: Myocardial infarction, Epidemiology, Mortality, Socio-economic, Elderly

\section{Background}

Socioeconomic status (SES) has been associated with mortality and incident coronary heart disease [1-3], and the Medicare entitlement program seeks to mitigate some of these SES differentials by providing universal access to healthcare to US citizens aged 65 years or

\footnotetext{
* Correspondence: coadys@nhlbi.nih.gov

${ }^{\dagger}$ Equal contributors

'Division of Cardiovascular Sciences, National Heart, Lung, and Blood Institute, 2 Rockledge Ctr, 6701 Rockledge Dr., Rm10200 MSC 7936, Bethesda 20817 MD, USA

Full list of author information is available at the end of the article
}

more. However, residing in areas with fewer economic resources may delay care for acute illness or impact the ability to receive routine or follow-up care. Further, despite Medicare's aspect of universal care, individual level SES may still impact health outcomes among the elderly through a variety of potential social-behavioral pathways such as chronic stress, a lack of social networks, and access to health information. Although socio-economic status has been shown to be related to all-cause mortality regardless of underlying disease [4], a disproportionate share of the disparities in mortality are due to 
chronic diseases [5]. An estimated 515,000 incident myocardial infarction (MI) cases occur in the US each year and with an average age $>65$ years, most are among the Medicare eligible population [6]. Approximately 22\% of those surviving the initial MI will have a recurrent event and mortality within the first year after an MI is as high as $30 \%$ [6]. Thus, furthering our understanding of the role of area and individual SES on survival and recurrence post MI among Medicare beneficiaries may have significant public health impacts.

Several international studies in locales with universal health care have found significant associations between area and/or individual socioeconomic traits with survival post MI [7-12]. Studies in North America have been less conclusive. In a large Medicare population, significant but modest associations were found for 30 day and 1 year mortality for beneficiaries residing in zip codes with the lowest median income [13], and in a Chicago based Medicare population, Medicaid recipients (defined as higher poverty status) in higher income zip codes did not have a survival benefit, while non-Medicaid recipients in zip codes with higher income had a lower mortality risk [14].

The National Longitudinal Mortality (NLMS) study was linked to Medicare records from 1991-2001 to assess associations between area income and individual education with mortality and recurrence in men and women 66 years of age or more after a first apparent MI. Mortality risk after an MI is initially high, but gradually improves over time. In the NLMS-Medicare sample cumulative mortality was $18 \%$ in the first 28 days, $32 \%$ at 1 year, and $56 \%$ at five years post MI. We hypothesized that differential associations may exist with respect to time since the index MI and that these associations may be further differentiated by sex or age. Factors associated with the area may exert a stronger influence on survival in the short term while individual factors may have a more pronounced association on longer term survival. In order to examine associations with both short and long term survival and recurrence, survival time was partitioned into 3 periods: in-hospital, discharge to 1 year, and 1 year to 5 year follow-up periods, and follow-up for recurrence was partitioned into 2 periods: 28 day to 1 year, and 1 to 5 years. Area SES was defined using the median income in the beneficiary's home zip code and individual SES was based on attained education.

\section{Methods}

\section{Data sources}

The NLMS is a prospective study of mortality occurring in combined samples of the non-institutionalized United States population drawn from the Census Bureau Annual Social and Economic Supplement (ASEC) ascertained in 1973 and annually from 1978-1998 [15]. Each survey sample is a complex, national probability sample of households surveyed to obtain demographic, economic, and social information about the U.S. population. During the household interview, information was collected on each occupant regarding age, sex, race, Hispanic status, educational attainment, and other socio-demographic characteristics.

Mortality follow-up information was collected through a computer match to the National Death Index (NDI) through 2002. The NDI, a national file containing information collected from death certificates, is maintained by the National Center for Health Statistics. The matching of records to the NDI has been shown to be an effective and accurate means of ascertaining mortality information using personal identifiers including: social security number, name, date of birth, sex, race, marital status, state of birth, and state of residence $[15,16]$. Each record match to the NDI is classified as either a true match, false match, or questionable match. All questionable matches are adjudicated by hand by comparing information on the death certificate to the matched ASEC record.

Morbidity and health care encounter data was obtained through record-linkage to the Centers for Medicare \& Medicaid Services (CMS) Medicare database. All NLMS persons with suitable identifiers were linked to Medicare data from 1991-2001. Of 458,772 NLMS persons that were age and survival eligible for Medicare and for which ASEC sample design information was available, 391,594 (85\%) were successfully linked. Those that were not linked to Medicare were similar to those linked to Medicare with respect to sex (56.0\% female vs $56.7 \%$ ), but were slightly younger (61.6 years of age on 1/1/1991 compared with 62.9 years of age), more likely to have an education level less than high school (41.2\% vs $36.4 \%)$, more likely to have a family income of less $\$ 10 \mathrm{~K}$ in 1990 dollars (26.6\% vs $16.6 \%)$, less likely to be married at time of survey $(65.6 \%$ vs $71.1 \%)$, more likely to be black (12.4\% vs $8.2 \%)$ and more likely to be Hispanic (6.1\% vs $3.9 \%)$. Since linkage to Medicare was related to SES, a sensitivity analysis was conducted in which the Medicare population was re-weighted adjusting for the probability of Medicare linkage. Medicare linkage probabilities were adjusted by sex, race, ethnicity, family income and marital status. Since the re-weighting was dependent on factors associated with Individual education, original weights will be the focus of the analysis. Enrollment information, hospital admissions, outpatient and physicians visits were extracted for each linked individual. Eligibility for the current study consisted of first hospitalizations with a primary or secondary discharge diagnosis code of 410 according to the ninth revision of the International Classification of Diseases Clinical Modification (ICD-CM 9), and continuous Medicare type $\mathrm{A}$ and $\mathrm{B}$ coverage for one year prior to the index 
MI. A primary or secondary discharge diagnosis code of 410 has been shown to have $94 \%$ positive predictive value (PPV) for identifying MIs in a Medicare population [17] and a PPV of approximately 75\% in the Atherosclerosis Risk in Communities study [18]. Since the year prior to the index MI was utilized for health related covariates, the minimum age for an MI was 66 years and the earliest date for an index MI was January 1, 1992. Exclusions included admissions from skilled nursing facilities, transfers from other health care facilities, and hospitalizations lasting more than 30 days. To isolate incident cases, ICD-CM9 discharge codes $410 . x 2$ were excluded as an indication of a repeat encounter, and persons with any mention of ICD9 codes 410 or 412 (old myocardial infarction) among the physician encounters, outpatient and hospital records for one year prior to the index MI were excluded.

\section{Covariates}

Procedure codes at the index hospitalization were searched for mention of coronary revascularization (Percutaneous Coronary intervention (PCI) 36.00-36.07, Coronary Artery Bypass Grafting (CABG) 36.10 - 3.6.19). Hospitalization, outpatient, and physician visit records for the year proceeding the MI were searched for any mention of a history of CHD (411, 413-414, 429.2), hypertension (401-404), hyperlipidemia (272.0 - 272.4), diabetes (250), or stroke (430 - 438). Sex and race were taken from the ASEC survey as these are self-reported, age in years was calculated from the date of MI and date of birth, and education was categorized into three groups based on the number of years of attained education: less than high school education, high school diploma but no college degree, college degree or more. Area SES was based on the home zip code at time of the index MI as extracted from the hospitalization record. Median income for all US zip codes was extracted from Census Bureau Zip Code Tabulation Areas Summary Tape Files for 1990 and 2000 and divided into quintiles. Zip Code Tabulation Areas are a geographic representation of postal service ZIP code service areas. Infarctions occurring in 1992-1995 were linked to median income quintiles in 1990 and all other MIs were linked to median income quintiles in 2000.

Since the ASEC survey may have occurred 20 years or more prior to enrollment in Medicare, individual measures of SES were limited to education. Due to low numbers, only those self-identifying as non-Hispanic white or black were included in the analysis.

\section{Outcome definitions}

Mortality follow-up was based on the NDI match and recurrence was defined as a subsequent hospitalization with a primary or secondary ICD9 discharge code of 410 or a CHD death defined as an ICD9 underlying cause of death code of 410-414 or ICD10 code of I20-I22, or I24I25. Any recorded MI within 28 days of the first MI was considered an extension of the first MI and not a recurrent event. Survival follow-up extended through December 31, 2002 while follow-up for recurrence was censored on December 31, 2001. Median follow-up time for survival was 6 years and median follow-up time for recurrence was 5 years.

\section{Statistical analysis}

All analyses were sex specific. To examine potential differential impacts according to follow-up time, survival analyses were conducted in 3 discrete time periods: in-hospital, discharge-1 year, and 1-5 years. Similarly, follow-up for recurrence was separated into 28 day- 1 year and 1-5 years. Since all persons had at least one year of follow-up for mortality, log-linear models were used to estimate relative risk associations with in-hospital and discharge-1 year mortality, and proportional hazards regression was used for long term survival and both 28 day- 1 year and 1-5 years recurrence. Earlier reports suggested that there may be effect modification by age with respect to SES associations [13]; therefore, analyses were further stratified into age specific groups: 66-79 years and $80+$ years. SUDAAN release 10.0.1 was used for all analyses to account for the complex sample design of the ASEC survey.

\section{Ethics}

The ASEC surveys are undertaken to characterize the US civilian, non-institutionalized population in terms of demographics and employment and therefore a traditional informed consent is not utilized. Participation is voluntary and subjects are informed that their data may be linked with other Census data or external data and are provided with the option to opt-out of any data linkage. The NLMS-Medicare study is a data linkage study without any direct interaction with survey respondents, thus the principles of the Helsinki Declaration are not applicable. The Medicare data linkage protocol was reviewed and approved by the Census Data Stewardship Executive Policy group and linkage to NDI further reviewed and approved by the National Association for Public Health Statistics and Information System (NAPHSIS) committee. As part of their review, these committees specifically evaluate the data security practices and participant privacy protections of studies conducting record linkage.

\section{Results}

The final sample included incident MIs from 8,043 women and 7,929 men. As shown in Table 1, the average age at time of MI was 79 years in women and 77 years in men. In both women and men, when compared to the older age 
Table 1 Basic characteristics of apparent first myocardial infarctions (MI) in NLMS persons linked to Medicare by sex and age group

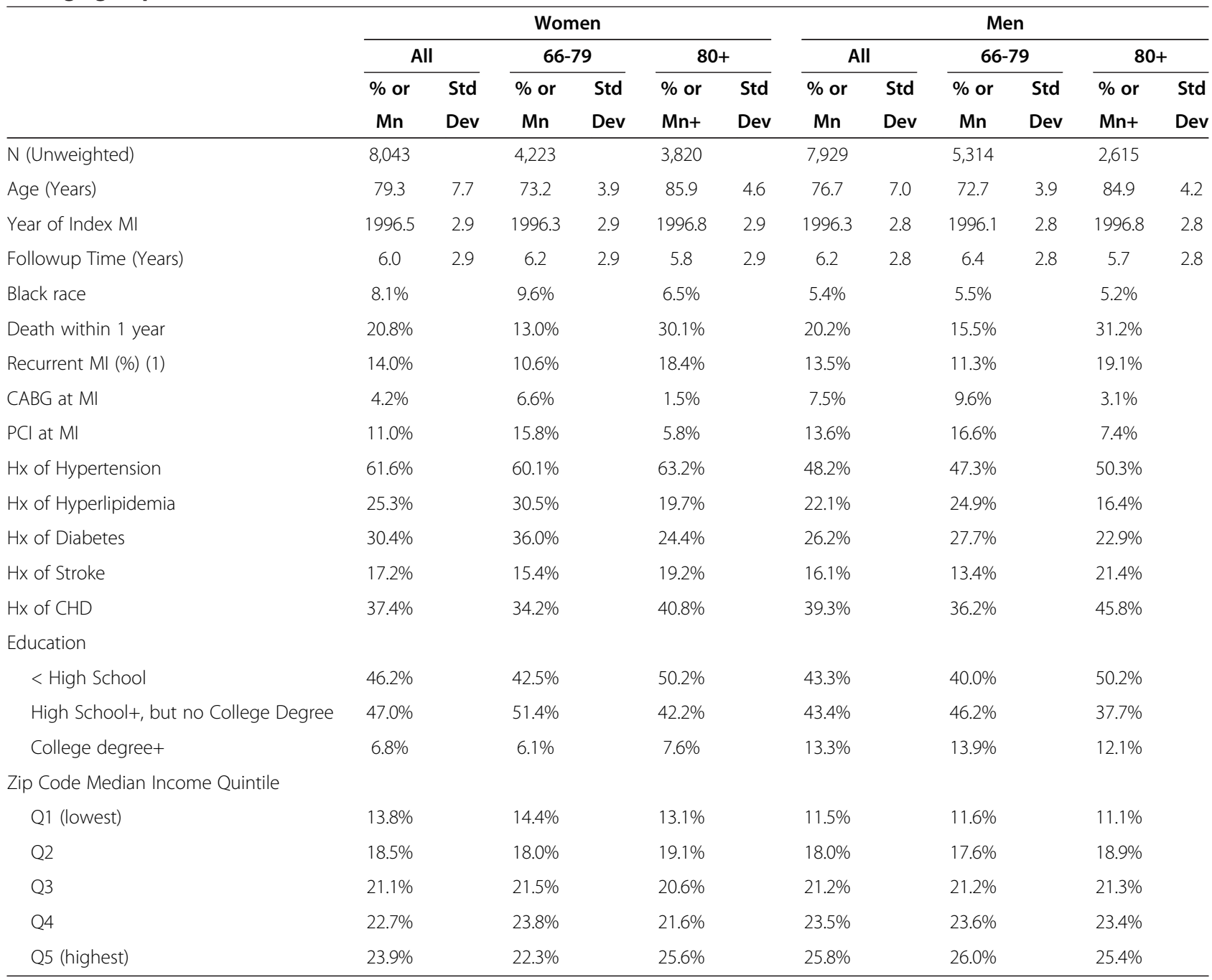

Abbreviations: $C A B G$ Coronary Artery Bypass Grafting, PCI Percutaneous coronary intervention, $C H D$ coronary heart disease.

(1) Recurrent Ml or fatal CHD event within 1 year among those surviving at least 28 days.

group (80+ years), coronary revascularizations at time of MI and a history of hyperlipidemia and diabetes were more likely to be noted among those in the younger age group. Those in the older age group were more likely to have a history of stroke or CHD. While the proportion with a college degree or more were similar by age group, those in the older age group were more likely to have less than a high school education. The MIs in the sample tended to come from higher income zip codes with approximately half of the sample from the top 2 quintiles of median income and approximately one third in the lower 2 quintiles.

\section{Survival}

All models were estimated with adjustment for age, race, history of hypertension, hyperlipidemia, diabetes, CHD, Stroke, PCI-CABG at hospitalization, and year of MI. Models were first run including only individual level education, a second run included only zip code level median income quintiles, and finally models were run including both individual level education and zip code median income quintiles. Adjustment for both individual level education and zip code median income quintile only marginally attenuated the risk ratios and hazard rates; therefore, only the fully adjusted results are presented.

As can be seen in Table 2 zip code level median income was not associated with survival in women. The exception, in-hospital mortality in women 66-79 years of age (RR Q1 v Q5 = 1.40; P = 0.037), was not significant in the sensitivity analysis (Additional file 1: Table S1). Individual level education was associated with 1-5 years mortality (HRR: < HS v College Degree $+=1.61, \mathrm{P}=.035$ ), but not with in-hospital or discharge-1 year mortality. Education and area SES were not associated with survival in women $80+$ years. 
Table 2 Association of education, and zip code median income quintile with in-hospital, discharge to 1 year, and 1-5 year mortality after a first apparent myocardial infarction in women

\begin{tabular}{|c|c|c|c|c|c|c|c|c|c|}
\hline & \multicolumn{3}{|c|}{ All women } & \multicolumn{3}{|c|}{ Women $66-79$ years } & \multicolumn{3}{|c|}{ Women $80+$ years } \\
\hline & RR or HRR & $95 \%$ Conf int & $P$ value & RR or HRR & $95 \%$ Conf int & $P$ value & RR or HRR & $95 \%$ Conf int & value \\
\hline \multicolumn{10}{|c|}{ In Hospital Mortality } \\
\hline $\mathrm{N}$ (Events) & 8,043 & (1153) & & 4,223 & (454) & & 3,820 & (699) & \\
\hline $\mathrm{Ed}<\mathrm{HS}$ & 1.07 & $(0.84,1.37)$ & 0.578 & 0.87 & $(0.58,1.31)$ & 0.518 & 1.18 & $(0.86,1.62)$ & 0.307 \\
\hline $\mathrm{Ed} \mathrm{HS}<\mathrm{BS}$ & 1.06 & $(0.83,1.35)$ & 0.644 & 0.78 & $(0.52,1.18)$ & 0.240 & 1.25 & $(0.92,1.71)$ & 0.156 \\
\hline Zip Inc q1 & 1.05 & $(0.86,1.28)$ & 0.640 & 1.40 & $(1.02,1.92)$ & 0.037 & 0.85 & $(0.65,1.11)$ & 0.245 \\
\hline Zip Inc q2 & 1.01 & $(0.84,1.20)$ & 0.931 & 1.18 & $(0.88,1.60)$ & 0.272 & 0.93 & $(0.74,1.16)$ & 0.511 \\
\hline Zip Inc q3 & 0.91 & $(0.76,1.09)$ & 0.332 & 0.99 & $(0.72,1.36)$ & 0.939 & 0.88 & $(0.71,1.10)$ & 0.268 \\
\hline Zip Inc q4 & 0.91 & $(0.76,1.08)$ & 0.261 & 0.89 & $(0.66,1.20)$ & 0.434 & 0.94 & $(0.76,1.17)$ & 0.596 \\
\hline \multicolumn{10}{|c|}{ Discharge - 365 day Mortality } \\
\hline $\mathrm{N}$ (Events) & 6,852 & (1392) & & 3,760 & $(484)$ & & 3,092 & (908) & \\
\hline $\mathrm{Ed}<\mathrm{HS}$ & 1.07 & $(0.87,1.32)$ & 0.516 & 1.23 & $(0.80,1.89)$ & 0.347 & 1.03 & $(0.82,1.31)$ & 0.779 \\
\hline $\mathrm{Ed} \mathrm{HS}<\mathrm{BS}$ & 0.95 & $(0.77,1.17)$ & 0.620 & 0.95 & $(0.62,1.47)$ & 0.834 & 0.97 & $(0.76,1.24)$ & 0.824 \\
\hline Zip Inc q1 & 1.02 & $(0.86,1.22)$ & 0.785 & 0.86 & $(0.62,1.20)$ & 0.377 & 1.10 & $(0.90,1.35)$ & 0.344 \\
\hline Zip Inc q2 & 1.05 & $(0.90,1.23)$ & 0.505 & 0.93 & $(0.70,1.24)$ & 0.626 & 1.10 & $(0.92,1.31)$ & 0.291 \\
\hline Zip Inc q33 & 0.98 & $(0.84,1.15)$ & 0.831 & 0.92 & $(0.69,1.22)$ & 0.546 & 1.01 & $(0.84,1.21)$ & 0.898 \\
\hline Zip Inc q4 & 0.98 & $(0.84,1.14)$ & 0.771 & 0.80 & $(0.59,1.09)$ & 0.158 & 1.07 & $(0.90,1.28)$ & 0.444 \\
\hline \multicolumn{10}{|c|}{366 days - 5 year Mortality } \\
\hline N (Events) & 5,460 & (729) & & 3,276 & (900) & & 2,184 & (1518) & \\
\hline $\mathrm{Ed}<\mathrm{HS}$ & 1.19 & $(0.95,1.50)$ & 0.138 & 1.61 & $(1.03,2.50)$ & 0.035 & 0.99 & $(0.76,1.30)$ & 0.962 \\
\hline $\mathrm{Ed} \mathrm{HS}<\mathrm{BS}$ & 1.08 & $(0.86,1.35)$ & 0.531 & 1.41 & $(0.92,2.18)$ & 0.117 & 0.91 & $(0.69,1.20)$ & 0.501 \\
\hline Zip Inc q1 & 1.00 & $(0.82,1.21)$ & 0.986 & 1.11 & $(0.83,1.47)$ & 0.486 & 0.93 & $(0.72,1.21)$ & 0.605 \\
\hline Zip Inc q2 & 0.95 & $(0.80,1.13)$ & 0.576 & 0.95 & $(0.73,1.24)$ & 0.721 & 0.96 & $(0.77,1.21)$ & 0.754 \\
\hline Zip Inc q3 & 0.94 & $(0.80,1.11)$ & 0.474 & 1.06 & $(0.83,1.35)$ & 0.656 & 0.86 & $(0.69,1.08)$ & 0.203 \\
\hline Zip Inc q4 & 1.01 & $(0.86,1.19)$ & 0.919 & 1.04 & $(0.82,1.32)$ & 0.756 & 1.00 & $(0.81,1.25)$ & 0.971 \\
\hline
\end{tabular}

Abbreviations: RR Relative Risk (In-hospital and Discharge - 365 day mortality), HRR Hazard Rate Ratio (1-5 year mortality), Ed $<$ HS Education less than a high school diploma, Ed HS < BS At least a high school

diploma, but no college degree.

Education referent group is college degree or more. Zip code median income referent group is quintile 5 (highest median income).

Italicized associations, confidence intervals, and p-values denote those significant at alpha $<0.05$. 
Similar to women, individual level education was associated with long term survival in men 66-79 years of age (Table 3, HRR: $<$ HS v College Degree $+=1.37$, $\mathrm{P}=.017$ ). The lowest quintile of zip code level median income was marginally associated with long term mortality in younger men (HRR Q1 v Q5 = 1.30; P = 0.052) in both the primary analysis and in the sensitivity analysis (Additional file 1: Table S2). Although zip code level median income was associated with discharge1 year mortality among men $80+$ years of age, these associations were not significant in the sensitivity analysis. No association was found between individual level education and short or long-term mortality in men $80+$ years of age.

\section{Recurrence}

Neither individual level education or zip code level median income were associated with recurrence in women (Table 4); however, education approached statistical significance with long-term recurrence in women $80+$ years of age (HRR: < HS v College Degree $+=1.52, \mathrm{P}=.064$ ). Contrary to expectations, zip code level median income in quintile 4 was associated with lower long-term recurrence $(\mathrm{Q} 4 \mathrm{v} \mathrm{Q} 5=0.65 ; \mathrm{P}=0.009)$, a potential false positive since all other associations were non-significant or above 1.0.

As shown in Table 5, individual level education was associated with long term recurrence (1-5 years) in men 66-79 years of age (HRR: $<$ HS v College Degree $+=1.68$, $\mathrm{P}=.004)$. No association was found for zip code level median income with short or long-term recurrence in men 66-79 years of age; however, in men $80+$ years of age, the lowest quintile of zip code level median income was associated with increased short term recurrence $(\mathrm{Q} 1$ $\mathrm{v} \mathrm{Q} 5=1.72, \mathrm{P}=0.009$ ).

\section{Discussion}

In the linked NLMS-Medicare sample, lower individual level education was associated with increased mortality in women and men 1-5 years after a first apparent MI. Education less than a high school diploma was associated with a $61 \%$ increase in 1-5 year mortality in women 66-79 years of age and a 37\% increase in 1-5 year mortality in men 66-79 years of age when compared to those with a college degree or more. Education below a high school diploma was also associated with a $68 \%$ increase in 1-5 year recurrence in men 66-79 years of age. While associations were largely limited to persons $66-79$ years of age, there was some evidence for an association of education with long-term recurrence in older (80+ years) women. Median zip code level income was inconsistently associated with mortality and recurrence. Median zip code income associations with mortality and recurrence were observed only in older ( $80+$ years) men.
Positive associations were found with discharge- 1 year mortality and 28 day- 1 year recurrence. Approximately $25 \%$ of the sample resided in zip codes that were in the highest quintile of median income, while less than 14\% resided in zip codes in the lowest quintile of median income substantiating, circumstantially, that surviving long enough to reach Medicare may be linked to area SES [5].

There is limited data concerning area or individual socioeconomic status with post MI outcomes in a Medicare population. In a large Medicare based study of over 130,000 MIs ascertained in 1994-1996, Rao et al. found that relative to those in the highest decile of zip code income, those in the lowest decile of income were at $25 \%$ greater risk of 30 day mortality and $14 \%$ greater risk of 1 year mortality [13]. These risks are comparable to those found in the present study in women for inhospital mortality and in men for discharge to 1 year mortality. In a study of 10,557 Medicare beneficiaries newly diagnosed with at least one condition (stroke, MI, heart failure, hip fracture or cancer) in 1993, Wen and Christakis utilized Census data and a social survey of neighborhood residents to examine mortality associations in different sociodemographic groups. Neighborhood characteristics included zip code measures of affluence, poverty, and education. Measures of the social environment were derived from the Project on Human Development in Chicago Neighborhoods Community Survey, and poverty status was based on an indicator for Medicaid recipient. Wen and Christakis found that zip code SES and social environment were associated with mortality to the extent that a 1 standard deviation decrease in either index was roughly equivalent to an extra year of life, but primarily among the 'non-poverty' group [14].

Studies in the US with a broader age range have generally found a lack of association with individual level education or income. In a study of 2,142 acute MIs from the PREMIER registry, Bernheim et al found that after adjustment, neither household income nor education was associated with one year survival [19], and after a follow-up of 2 years, Alter et al found that among 3,407 patients hospitalized with acute MI in Ontario, Canada, the association of income with mortality was no longer significant after adjustment for conventional risk factors and preexisting cardiovascular events [20]. However, area SES has generally been positively associated with mortality in studies with a broader age range. Using multi-level proportional hazards models, Tonne et al found in the Worcester Massachusetts Heart Attack Study that among 3,423 acute MI cases, those in Census tracts with the highest income or education had significantly better survival [21], and among 705 acute MIs in Olmsted county, Minnesota, lower Census tract income 
Table 3 Association of education, and zip code median income quintile with in-hospital, discharge to 1 year, and 1-5 year mortality after a first apparent myocardial infarction in men

\begin{tabular}{|c|c|c|c|c|c|c|c|c|c|}
\hline & \multicolumn{3}{|c|}{ All men } & \multicolumn{3}{|c|}{ Men 66-79 years } & \multicolumn{3}{|c|}{ Men $80+$ years } \\
\hline & RR or HRR & $95 \%$ Conf int & $P$ value & RR or HRR & $95 \%$ Conf int & $P$ value & RR or HRR & 95\% Conf int & $P$ value \\
\hline \multicolumn{10}{|c|}{ In Hospital Mortality } \\
\hline$N$ (Events) & 7,929 & $(1059)$ & & 5,314 & (527) & & 2,615 & (532) & \\
\hline $\mathrm{Ed}<\mathrm{HS}$ & 1.07 & $(0.87,1.31)$ & 0.544 & 1.06 & $(0.78,1.43)$ & 0.720 & 1.09 & $(0.82,1.43)$ & 0.558 \\
\hline $\mathrm{Ed} \mathrm{HS}<\mathrm{BS}$ & 1.02 & $(0.83,1.26)$ & 0.819 & 1.04 & $(0.77,1.40)$ & 0.812 & 1.01 & $(0.76,1.34)$ & 0.955 \\
\hline Zip Inc q1 & 1.06 & $(0.84,1.33)$ & 0.636 & 1.08 & $(0.78,1.49)$ & 0.648 & 1.03 & $(0.74,1.42)$ & 0.875 \\
\hline Zip Inc q2 & 1.04 & $(0.85,1.27)$ & 0.707 & 1.03 & $(0.77,1.39)$ & 0.831 & 1.05 & $(0.80,1.36)$ & 0.739 \\
\hline Zip Inc q3 & 1.14 & $(0.95,1.38)$ & 0.165 & 1.19 & $(0.90,1.57)$ & 0.227 & 1.10 & $(0.86,1.42)$ & 0.442 \\
\hline Zip Inc q4 & 1.04 & $(0.87,1.25)$ & 0.659 & 0.92 & $(0.69,1.21)$ & 0.538 & 1.17 & $(0.92,1.49)$ & 0.198 \\
\hline \multicolumn{10}{|c|}{ Discharge - 365 day Mortality } \\
\hline $\mathrm{N}$ (Events) & 6,850 & $(1377)$ & & 4,776 & (709) & & 2,074 & (668) & \\
\hline $\mathrm{Ed}<\mathrm{HS}$ & 1.00 & $(0.85,1.17)$ & 0.953 & 0.99 & $(0.78,1.25)$ & 0.918 & 1.00 & $(0.80,1.25)$ & 0.978 \\
\hline $\mathrm{Ed} \mathrm{HS}<\mathrm{BS}$ & 0.97 & $(0.82,1.14)$ & 0.685 & 0.90 & $(0.71,1.14)$ & 0.374 & 1.04 & $(0.83,1.31)$ & 0.714 \\
\hline Zip Inc q1 & 1.24 & $(1.04,1.48)$ & 0.016 & 1.15 & $(0.88,1.49)$ & 0.303 & 1.31 & $(1.03,1.67)$ & 0.026 \\
\hline Zip Inc q2 & 1.07 & $(0.92,1.26)$ & 0.379 & 0.92 & $(0.72,1.17)$ & 0.486 & 1.25 & $(1.02,1.54)$ & 0.031 \\
\hline Zip Inc q3 & 1.03 & $(0.88,1.21)$ & 0.709 & 0.95 & $(0.75,1.20)$ & 0.663 & 1.13 & $(0.92,1.39)$ & 0.254 \\
\hline Zip Inc q4 & 1.15 & $(0.99,1.33)$ & 0.072 & 1.05 & $(0.84,1.31)$ & 0.669 & 1.25 & $(1.03,1.52)$ & 0.027 \\
\hline \multicolumn{10}{|c|}{366 days - 5 year Mortality } \\
\hline N (Events) & 5,473 & (1518) & & 4,067 & (901) & & 1,406 & $(617)$ & \\
\hline $\mathrm{Ed}<\mathrm{HS}$ & 1.21 & $(0.99,1.48)$ & 0.066 & 1.37 & $(1.06,1.76)$ & 0.017 & 0.99 & $(0.71,1.40)$ & 0.969 \\
\hline $\mathrm{Ed} \mathrm{HS}<\mathrm{BS}$ & 1.27 & $(1.04,1.55)$ & 0.021 & 1.32 & $(1.03,1.69)$ & 0.030 & 1.16 & $(0.82,1.64)$ & 0.393 \\
\hline Zip Inc q1 & 1.30 & $(1.07,1.59)$ & 0.009 & 1.30 & $(1.00,1.69)$ & 0.052 & 1.33 & $(0.98,1.81)$ & 0.068 \\
\hline Zip Inc q2 & 1.03 & $(0.86,1.24)$ & 0.739 & 1.07 & $(0.85,1.34)$ & 0.576 & 0.99 & $(0.73,1.33)$ & 0.921 \\
\hline Zip Inc q3 & 0.95 & $(0.80,1.13)$ & 0.588 & 1.03 & $(0.83,1.28)$ & 0.785 & 0.86 & $(0.65,1.14)$ & 0.306 \\
\hline Zip Inc q4 & 1.13 & $(0.96,1.33)$ & 0.146 & 1.07 & $(0.87,1.32)$ & 0.516 & 1.25 & $(0.97,1.61)$ & 0.091 \\
\hline
\end{tabular}

Abbreviations: RR Relative Risk (In-hospital and Discharge - 365 day mortality), HRR Hazard Rate Ratio (1-5 year mortality), Ed < HS Education less than a high school diploma, Ed HS < BS At least a high school diploma, but no college degree.

Adjusted for Age, race, hx of hypertension, hx of diabetes, hx of lipidemia, hx of CHD, hx of stroke, and coronary revascularization (PCl or CABG) during hospitalization, year of MI.

Education referent group is college degree or more. Zip code median income referent group is quintile 5 (highest median income).

Education referent group is college degree or more. Zip code median income referent group is quin 
Table 4 Association of education, and zip code median income quintile with recurrent myocardial infarction or fatal CHD within 1 year or 1-5 years in women surviving 28 days after a first apparent myocardial infarction

\begin{tabular}{|c|c|c|c|c|c|c|c|c|c|}
\hline & \multicolumn{3}{|c|}{ All women } & \multicolumn{3}{|c|}{ Women $66-79$ years } & \multicolumn{3}{|c|}{ Women $80+$ years } \\
\hline & HRR & $95 \%$ Conf int & $P$ value & HRR & $95 \%$ Conf int & $P$ value & HRR & $95 \%$ Conf int & $P$ value \\
\hline \multicolumn{10}{|c|}{ Recurrent MI/Fatal CHD (29 days-365 days) } \\
\hline$N$ (Events) & 6,528 & (889) & & 3,646 & (375) & & 2,882 & (514) & \\
\hline $\mathrm{Ed}<\mathrm{HS}$ & 1.07 & $(0.77,1.48)$ & 0.698 & 1.40 & $(0.79,2.48)$ & 0.245 & 0.97 & $(0.65,1.44)$ & 0.869 \\
\hline $\mathrm{Ed} \mathrm{HS}<\mathrm{BS}$ & 1.01 & $(0.73,1.40)$ & 0.957 & 1.44 & $(0.82,2.55)$ & 0.206 & 0.87 & $(0.58,1.31)$ & 0.504 \\
\hline Zip Inc q1 & 1.02 & $(0.77,1.33)$ & 0.914 & 0.89 & $(0.59,1.32)$ & 0.555 & 1.11 & $(0.77,1.60)$ & 0.580 \\
\hline Zip Inc q2 & 1.09 & $(0.86,1.39)$ & 0.465 & 0.91 & $(0.64,1.29)$ & 0.602 & 1.24 & $(0.90,1.71)$ & 0.198 \\
\hline Zip Inc q3 & 1.04 & $(0.83,1.30)$ & 0.740 & 0.87 & $(0.62,1.20)$ & 0.394 & 1.19 & $(0.88,1.60)$ & 0.263 \\
\hline Zip Inc q4 & 1.00 & $(0.80,1.25)$ & 0.983 & 0.81 & $(0.58,1.14)$ & 0.228 & 1.17 & $(0.87,1.59)$ & 0.296 \\
\hline \multicolumn{10}{|c|}{ Recurrent MI/Fatal CHD (366 days- 5 years) } \\
\hline$N$ (Events) & 4,681 & (833) & & 2,837 & $(402)$ & & 1,844 & $(431)$ & \\
\hline $\mathrm{Ed}<\mathrm{HS}$ & 1.36 & $(0.99,1.88)$ & 0.060 & 1.19 & $(0.76,1.88)$ & 0.445 & 1.52 & $(0.98,2.37)$ & 0.064 \\
\hline $\mathrm{Ed} \mathrm{HS}<\mathrm{BS}$ & 1.17 & $(0.85,1.62)$ & 0.335 & 0.92 & $(0.58,1.44)$ & 0.700 & 1.46 & $(0.94,2.27)$ & 0.096 \\
\hline Zip Inc q1 & 0.80 & $(0.61,1.05)$ & 0.104 & 0.78 & $(0.52,1.17)$ & 0.226 & 0.82 & $(0.57,1.19)$ & 0.300 \\
\hline Zip Inc q2 & 0.97 & $(0.77,1.22)$ & 0.816 & 1.06 & $(0.77,1.46)$ & 0.717 & 0.89 & $(0.65,1.23)$ & 0.493 \\
\hline Zip Inc q3 & 0.88 & $(0.71,1.09)$ & 0.235 & 0.88 & $(0.64,1.20)$ & 0.421 & 0.89 & $(0.66,1.20)$ & 0.429 \\
\hline Zip Inc q4 & 0.70 & $(0.56,0.87)$ & 0.002 & 0.75 & $(0.54,1.03)$ & 0.072 & 0.65 & $(0.47,0.90)$ & 0.009 \\
\hline
\end{tabular}

Abbreviations: HRR Hazard Rate Ratio, Ed < HS Education less than a high school diploma, Ed HS < BS At least a high school diploma, but no college degree.

Adjusted for Age, race, hx of hypertension, hx of diabetes, hx of lipidemia, hx of CHD, hx of stroke, and coronary revascularization (PCl or CABG) during hospitalization, year of Ml.

Education referent group is college degree or more. Zip code median income referent group is quintile 5 (highest median income).

Italicized associations, confidence intervals, and p-values denote those significant at alpha $<0.05$. 
Table 5 Association of education, and zip code median income quintile with recurrent myocardial infarction or fatal CHD within 1 year or 1-5 years in men surviving 28 days after a first apparent myocardial infarction

\begin{tabular}{|c|c|c|c|c|c|c|c|c|c|}
\hline & \multicolumn{3}{|c|}{ All men } & \multicolumn{3}{|c|}{ Men $66-79$ years } & \multicolumn{3}{|c|}{ Men $80+$ years } \\
\hline & HRR & $95 \%$ Conf int & Pvalue & HRR & $95 \%$ Conf int & $P$ value & HRR & $95 \%$ Conf int & $P$ value \\
\hline \multicolumn{10}{|c|}{ Recurrent MI/Fatal CHD (29 days-365 days) } \\
\hline$N$ (Events) & 6,493 & (832) & & 4,584 & $(484)$ & & 1,909 & (348) & \\
\hline $\mathrm{Ed}<\mathrm{HS}$ & 1.01 & $(0.79,1.30)$ & 0.908 & 1.12 & $(0.83,1.52)$ & 0.455 & 0.89 & $(0.59,1.35)$ & 0.581 \\
\hline $\mathrm{Ed} \mathrm{HS}<\mathrm{BS}$ & 0.80 & $(0.62,1.02)$ & 0.076 & 0.74 & $(0.54,1.00)$ & 0.050 & 0.91 & $(0.59,1.40)$ & 0.681 \\
\hline Zip Inc q1 & 1.28 & $(0.99,1.66)$ & 0.065 & 1.03 & $(0.73,1.46)$ & 0.864 & 1.72 & $(1.14,2.57)$ & 0.009 \\
\hline Zip Inc q2 & 1.20 & $(0.96,1.52)$ & 0.113 & 1.13 & $(0.84,1.52)$ & 0.403 & 1.30 & $(0.90,1.89)$ & 0.162 \\
\hline Zip Inc q3 & 0.90 & $(0.71,1.14)$ & 0.393 & 0.82 & $(0.61,1.11)$ & 0.200 & 1.04 & $(0.71,1.51)$ & 0.857 \\
\hline Zip Inc q4 & 1.13 & $(0.91,1.41)$ & 0.257 & 0.98 & $(0.74,1.29)$ & 0.886 & 1.38 & $(0.98,1.95)$ & 0.064 \\
\hline \multicolumn{10}{|c|}{ Recurrent MI/Fatal CHD (366 days- 5 years) } \\
\hline$N$ (Events) & 4,778 & (774) & & 3,602 & (494) & & 1,176 & $(280)$ & \\
\hline $\mathrm{Ed}<\mathrm{HS}$ & 1.49 & $(1.11,2.00)$ & 0.008 & 1.68 & $(1.18,2.41)$ & 0.004 & 1.18 & $(0.71,1.96)$ & 0.532 \\
\hline $\mathrm{Ed} \mathrm{HS}<\mathrm{BS}$ & 1.39 & $(1.04,1.86)$ & 0.027 & 1.46 & $(1.02,2.08)$ & 0.038 & 1.32 & $(0.79,2.21)$ & 0.292 \\
\hline Zip Inc q1 & 1.24 & $(0.93,1.65)$ & 0.151 & 1.22 & $(0.84,1.78)$ & 0.288 & 1.26 & $(0.78,2.03)$ & 0.342 \\
\hline Zip Inc q2 & 1.13 & $(0.88,1.45)$ & 0.329 & 1.19 & $(0.88,1.62)$ & 0.262 & 1.04 & $(0.68,1.60)$ & 0.857 \\
\hline Zip Inc q3 & 1.00 & $(0.79,1.27)$ & 0.978 & 1.01 & $(0.75,1.36)$ & 0.956 & 1.01 & $(0.68,1.51)$ & 0.952 \\
\hline Zip Inc q4 & 1.09 & $(0.86,1.37)$ & 0.482 & 0.99 & $(0.74,1.33)$ & 0.942 & 1.31 & $(0.89,1.92)$ & 0.172 \\
\hline
\end{tabular}

Abbreviations: HRR Hazard Rate Ratio, Ed < HS Education less than a high school diploma, Ed HS $<$ BS At least a high school diploma, but no college degree.

Adjusted for Age, race, hx of hypertension, hx of diabetes, hx of lipidemia, hx of CHD, hx of stroke, and coronary revascularization (PCl or CABG) during hospitalization, year of first MI.

Adjusted for Age,

Zip code median income referent group is quintile 5 (highest median income).

Italicized associations, confidence intervals, and p-values denote those significant at alpha $<0.05$. 
was associated with mortality while individual level education was not [22]. Likewise, after an average follow-up of three years, Horne et al found that zip code level median income was associated with a combined endpoint of death/MI among 3,410 Salt Lake City patients with angiographically defined coronary artery disease [23].

The Medicare program has been shown to reduce differentials in the control of key cardiovascular risk factors such as blood pressure, glucose, and cholesterol [24], but despite these gains, there are potential mechanisms by which all persons may not benefit equally. Residing in more disadvantaged Census tracts has been associated with a longer pre-hospital delay $[13,25]$, and lower likelihood of being treated at hospitals with catheterization facilities [13] potentially impacting directly the in-hospital prognosis. Survival at high volume hospitals has been shown to be better when compared to lower volume hospitals [26], but it is unclear if a correlation exists between use of high volume hospitals and area characteristics.

Individual level SES has previously been associated with cardiac rehabilitation in a Medicare population [27], and among survivors of MI, those with lower individual income or education were shown to be more likely to smoke, less likely to exercise, and more likely to consume alcohol [28] potentially impacting the longer term prognosis. Associations were more pronounced for income rather than education however, suggesting that income may detect stronger mortality gradients than education in an elderly population.

The NLMS-Medicare dataset offers the advantage of a large, nationally representative sample with self-reported measures of race and education. The relatively large size also permitted stratifying the sample by subgroups of interest, particularly sex, age and time since the initial MI. However, there are limitations that should be acknowledged. While the previous year's medical history was used to define covariates, we were unable to account for some potential confounders such as hospital characteristics, smoking or medications. Interview dates for the ASEC survey could have been as many as 20 years prior to the index MI and given the varying lengths of time, we were limited to education as the sole indicator of individual SES. Individual SES is a multi-dimensional trait and characteristics such as income or social networks may be more reflective of socio-economic status in the elderly $[29,30]$. While geographic subdivisions such as Census tract or block define residential areas for the purpose of statistical reporting, zip codes are defined by the postal service as a means of efficiently delivering the mail and can thus change over time or be too heterogeneous to adequately reflect the neighborhood of an individual; however, in an incident MI case-control study in Washington state, the association of area characteristics such as median income or education with mortality were not found to be sensitive to the neighborhood definition used (1 km buffer, block group, census tract, zip code) [31].

\section{Conclusions}

Area and individual socioeconomic characteristics acted independently on survival and recurrence post-MI among Medicare beneficiaries, and acted differentially with respect to time since the initial MI. With the exception of older men, area SES was largely not associated with survival or recurrence. Individual level education tended to impact longer term prognosis in both men and women. Future studies on differentials in survival and recurrence are needed to further our understanding of what barriers to immediate care may exist for persons residing in disadvantaged areas and on methods for improving access to longer term care.

\section{Additional file}

Additional file 1: SurvivalRecurrenceAfterMI_Medicare.pdf, supplementary tables with sensitivity results derived from re-weighting the Medicare sample to account for the probability of linkage to Medicare.

\section{Competing interests}

The authors have no actual or potential conflicts of interests.

\section{Authors' contributions}

SAC conceived the study, carried out the analysis and prepared the manuscript draft, NJJ collected the data and carried out the Medicare linkage and provided critical comments, JKH participated in analysis and provided critical comments on the manuscript, PDS participated in the design of the study and provided critical comments on the manuscript. All authors read and approved the final manuscript.

\section{Acknowledgments}

Any views expressed on statistical, methodological, technical, or operational issues are those of the authors and not necessarily those of the U.S. Census Bureau. This work was supported by an Interagency Agreement between the National Heart, Lung and Blood Institute and the United States Bureau of the Census (IAA No. A-HL-12-005-001-01001).

\section{Author details}

${ }^{1}$ Division of Cardiovascular Sciences, National Heart, Lung, and Blood Institute, 2 Rockledge Ctr, 6701 Rockledge Dr., Rm10200 MSC 7936, Bethesda 20817 MD, USA. ${ }^{2}$ Center for Administrative Records and Research Applications, United States Bureau of the Census, 4600 Silver Hill Road, Suitland 20233 MD, USA.

Received: 23 October 2013 Accepted: 9 June 2014

Published: 9 July 2014

\section{References}

1. Marmot MG, Shipley MJ, Hemingway H, Head J, Brunner EJ: Biological and behavioural explanations of social inequalities in coronary heart disease: the Whitehall II study. Diabetologia 2008, 51:1980-1988.

2. Loucks EB, Lynch JW, Pilote L, Fuhrer R, Almeida ND, Richard H, Agha G, Murabito JM, Benjamin EJ: Life-course socioeconomic position and incidence of coronary heart disease: the Framingham Offspring Study. Am J Epidemiol 2008, 169:829-836.

3. Galobardes B, Smith GD, Lynch JW: Systematic review of the influence of childhood socioeconomic circumstances on risk for cardiovascular disease in adulthood. Ann Epidemiol 2006, 16:91-104. 
4. Sorlie PD, Backlund E, Keller JB: US mortality by economic, demographic, and social characteristics: the National Longitudinal Mortality Study. Ann J Public Health 1995, 85:949-956.

5. Murray CJL, Kulkarni SC, Michaud C, Tomijima N, Bulzacchelli MT, landiorio TJ, Ezzati M: Eight Americas: investigating mortality disparities across races, counties, and race-counties in the United States. PLoS Med 2006, 3:e260.

6. Go AS, Mozaffarian D, Roger VL, Benjamin EJ, Berry JD, Blaha MJ, Dai S, Ford ES, Fox CS, Franco S, Fullerton HJ, Gillespie C, Hailpern SM, Heit JA, Howard VJ, Huffman MD, Judd SE, Kissela BM, Kittner SJ, Lackland DT, Lichtman JH, Lisabeth LD, Mackey RH, Magid DJ, Marcus GM, Marelli A, Matchar DB, McGuire DK, Mohler ER III, Moy CS, et al: Heart disease and stroke statistics-2014 update: a report from the American Heart Association. Circulation 2014, 129:e28-e292.

7. Alter DA, Naylor D, Austin P, Tu JV: Effects of socioeconomic status on access to invasive cardiac procedures and on mortality after acute myocardial infarction. N Engl J Med 1999, 341:1359-1367.

8. Gerber Y, Benyamini Y, Goldbourt U, Drory Y: Neighborhood socioeconomic context and long-term survival after myocardial infarction. Circulation 2010 121:375-383.

9. Rosvall M, Chaix B, Lynch J, Lindström M, Merlo J: The association between socioeconomic position, use of revascularization procedures and five-year survival after recovery from acute myocardial infarction. BMC Public Health 2008, 8:44

10. Tydén P, Hansen O, Engström G, Hedblad B, Janzon L: Myocardial infarction in an urban population: worse long term prognosis for patients from less affluent residential areas. J Epidemiol Community Health 2002, 56:785-790.

11. Barakat K, Stevenson S, Wilkinson P, Suliman A, Ranjadayalan K, Timmis AD Socioeconomic differentials in recurrent ischaemia and mortality after acute myocardial infarction. Heart 2001, 85:390-394.

12. Rasmussen JN, Rasmussen S, Gislason GH, Buch P, Abildstrom SZ, Køber L, Osler M, Diderichsen F, Torp-Pedersen C, Madsen M: Mortality after acute myocardial infarction according to income and education. J Epidemiol Community Health 2006, 60:351-356.

13. Rao SV, Schulman KA, Curtis LH, Gersh BJ, Jollis JG: Socioeconomic status and outcome following acute myocardial infarction in elderly patients. Arch Intern Med 2004, 164:1128-1133.

14. Wen M, Christakis NA: Neighborhood effects on posthospitalization mortality: a population-based cohort study of the elderly in Chicago. Health Serv Res 2005, 40:1108-1127.

15. Rogot E, Sorlie $P$, Johnson NJ: Probabilistic methods in matching census samples to the National Death Index. J Chronic Dis 1986, 39:719-734.

16. Rogot E, Feinleib M, Ockay K, Schwartz S, Bilgrad R, Patterson J: On the feasibility of linking census samples to the national death index for epidemiologic studies: a progress report. Am J Public Health 1983, 73:1265-1269.

17. Kiyota Y, Schneeweiss S, Glynn RJ, Cannuscio CC, Avorn J, Solomon DH: Accuracy of Medicare claims-based diagnosis of acute myocardial infarction: estimating positive predictive value on the basis of review of hospital records. Am Heart J 2004, 148:99-104.

18. Rosamond WD, Chambless LE, Sorlie PD, Bell EM, Weitzman S, Smith JC, Folsom AR: Trends in the Sensitivity, Positive Predictive Value, False-Positive Rate, and Comparability Ratio of Hospital Discharge Diagnosis Codes for Acute Myocardial Infarction in Four US Communities, 1987-2000. Am J Epidemio/ 2004, 160:1137-1146.

19. Bernheim SM, Spertus JA, Reid KJ, Bradley EH, Desai RA, Peterson ED, Rathore S, Normand ST, Jones PG, Rahimi A, Krumholz HM: Socioeconomic disparities in outcomes after acute myocardial infarction. Am Heart J 2007, 153:313-319.

20. Alter DA, Chong A, Austin PC, Mustard C, Iron K, Williams JI, Morgan CD, Tu $J V$, Irvine J, Naylor CD: Socioeconomic Status and Mortality after Acute Myocardial Infarction. Ann Intern Med 2006, 144:82-93.

21. Tonne C, Schwartz J, Mittleman M, Melly S, Suh H, Goldberg R: Long-term survival after acute myocardial infarction is lower in more deprived neighborhoods. Circulation 2005, 111:3063-3070.

22. Gerber Y, Weston SA, Killian JM, Therneau TM, Jacobsen SJ, Roger VL: Neighborhood income and individual education: effect on survival after myocardial infarction. Mayo Clin Proc 2008, 83:663-669.

23. Horne BD, Muhlestein JB, Lappé DL, Renlund DG, Bair TL, Bunch TJ, Anderson $J$ L: Less affluent area of residence and lesser-insured status predict an increased risk of death or myocardial infarction after angiographic diagnosis of coronary disease. Ann Epidemiol 2004 14:143-150

24. McWilliams MJ, Meara E, Zaslavsky AM, Ayanian JZ: Differences in control of cardiovascular disease and diabetes by race, ethnicity, and education: U.S. Trends from 1999 to 2006 and effects of Medicare coverage. Ann Intern Med 2009, 150:505-515.

25. Foraker RE, Rose KM, McGinn AP, Suchindran CM, Goff DCJ, Whitsel EA Wood $J$, Rosamond WD: Neighborhood income, health insurance, and prehospital delay for myocardial infarction. Arch Intern Med 2008, 168:1874-1879.

26. Thiemann DR, Coresh J, Oetgen WJ, Powe NR: The association between hospital volume and survival after acute myocardial infarction in elderly patients. N Engl J Med 1999, 340:1640-1648.

27. Suaya JA, Shepard DS, Normand S-LT, Ades PA, Prottas J, Stason WB: Use of cardiac rehabilitation by Medicare beneficiaries after myocardial infarction or coronary bypass surgery. Circulation 2007, 116:1653-1662.

28. Chan RHM, Gordon NF, Chong A, Alter DA: Influence of socioeconomic status on lifestyle behavior modifications among survivors of acute myocardial infarction. Am J Cardiol 2008, 102:1583-1588.

29. Braveman PA, Cubbin C, Egerter S, Chideya S, Marchi KS, Metzler M, Posner S: Socioeconomic status in health research: one size does Not Fit All. JAMA 2005, 294:2879-2888.

30. Oakes JM, Rossi PH: The measurement of SES in health research: current practice and steps toward a new approach. Soc Sci Med 2003, 56:769-784.

31. Lovasi GS, Moudon AV, Smith NL, Lumley T, Larson EB, Sohn DW, Siscovick DS, Psaty BM: Evaluating options for measurement of neighborhood socioeconomic context: evidence from a myocardial infarction case-control study. Health Place 2008, 14:453-467.

doi:10.1186/1471-2458-14-705

Cite this article as: Coady et al:: Individual education, area income, and mortality and recurrence of myocardial infarction in a Medicare cohort: the National Longitudinal Mortality Study. BMC Public Health 2014 14:705.

\section{Submit your next manuscript to BioMed Central and take full advantage of:}

- Convenient online submission

- Thorough peer review

- No space constraints or color figure charges

- Immediate publication on acceptance

- Inclusion in PubMed, CAS, Scopus and Google Scholar

- Research which is freely available for redistribution

Submit your manuscript at www.biomedcentral.com/submit
C Biomed Central 